\title{
Antimicrobial susceptibility patterns of bacteria isolated from patients with ear discharge in Jimma Town, Southwest, Ethiopia
}

Kasahun Gorems' ${ }^{1}$ Getenet Beyene', Melkamu Berhane ${ }^{2}$ and Zeleke Mekonnen ${ }^{1 *}$

\begin{abstract}
Background: Otitis media is among the leading causes of childhood illnesses although it can also affect the adults resulting in frequent physician visits, drug prescription and a key contributor to antibiotic resistance. The aim of this study was to determine the risk factors, bacterial profile, and the antimicrobial susceptibility pattern of the isolates from patients with discharging ears which clinically equates to draining otitis media in developing countries with limited medical resources such as otoscope.

Methods: A prospective cross-sectional study was conducted on 173 patients with draining otitis media. The ear discharge specimens were collected and analyzed by standard microbial techniques. The antibiotic susceptibility profiles were determined for 19 different antibiotics by the standard disk diffusion method. Data was analyzed by SPSS version 22 and the $P$ value of less than 0.05 was considered as statistically significant.

Results: Among 173 otitis media patients participated in the study; majority, 102(63\%) were pediatrics, out of which $72(41.61 \%)$ were in the age group of less than 4 years. Ear infection was bilateral in 39 (22.54\%) and chronic in 100 (57.8\%) of the patients. Pathogens were isolated from 160 (92.5\%) of the patients with a total of 179 isolates. The predominant isolate was Staphylococcus aureus (30.72\%) followed by Proteus spp. (17.89\%). The result of this study showed that adult age $(p=0.031)$, rural residence $(p=0.005)$, previous history of health care visit and treatment $(p$ $=0.000)$, upper respiratory tract infection $(p=0.018)$ and presence of cigarette smoker in the house $(p=0.022)$ had statistically significant association with chronic otitis media. Most of the isolated bacteria showed high level of resistance to ampicillin/amoxicillin (88.3\%), penicillin G (79.5\%) followed by trimethoprim /sulfamethoxazole (73.8\%). Conversely, the majority of bacterial isolates showed moderate susceptibility to ciprofloxacin (72.9\%), gentamicin (70.4\%), and amikacin (69.3\%). Bacterial isolates identified in this study showed trend of multiple drug resistance, majority (67\%) being resistant to three or more antimicrobials.
\end{abstract}

Conclusions: Majority of the bacterial isolates were multidrug resistant, hence, efforts to isolate microorganisms and determine the susceptibility pattern should be strengthened to improve the treatment outcome of otitis media instead of the usual trend of empirical treatment.

Keywords: Otitis media, Antimicrobial, Susceptibility, Jimma, Ethiopia

\footnotetext{
* Correspondence: zeleke.mekonnen@ju.edu.et

${ }^{1}$ School of Medical Laboratory Sciences, Institute of Health, Jimma University,

P.O. Box 378, Jimma, Ethiopia

Full list of author information is available at the end of the article
}

(c) The Author(s). 2018 Open Access This article is distributed under the terms of the Creative Commons Attribution 4.0 International License (http://creativecommons.org/licenses/by/4.0/), which permits unrestricted use, distribution, and reproduction in any medium, provided you give appropriate credit to the original author(s) and the source, provide a link to the Creative Commons license, and indicate if changes were made. The Creative Commons Public Domain Dedication waiver (http://creativecommons.org/publicdomain/zero/1.0/) applies to the data made available in this article, unless otherwise stated. 


\section{Background}

Ear infection which can be classified into otitis media $(\mathrm{OM})$ and otitis externa, is a major public health concern in developing countries associated with high burden of disease and economic impact to patients, families and the health care system. It is one of the most frequently encountered illnesses in children leading to repeated outpatient department (OPD) visits in both developed and developing countries even if it can also affect the adults [1].

$\mathrm{OM}$ is a continuum of disorders ranging from a simple acute otitis media (AOM) to recurrent acute otitis media (RAOM), otitis media with effusion (OME) or chronic otitis media (COM) [2]. Untreated or inadequately treated $\mathrm{OM}$ due to either inaccurate diagnosis or inappropriate use of antibiotics leads to purulent otitis, often with perforation and further complications including RAOM, persistence of middle ear effusion which requires the insertion of drainage tube and often leads to hearing impairment, mastoiditis, meningitis, COM, brain abscess and sepsis [3, 4]. It also leads to impaired speech and language development, poor school performance and impaired social interaction [5]. Moreover, otitis externa is an infection of the outer ear canal commoner in patients who have eczema and or diabetes.

Diagnosis of OM is complicated by a lack of correlation between clinical features and responsible pathogens and drug susceptibility pattern. Additionally, routine unavailability of an othoscope in many of the health facilities particularly in the developing countries which is necessary to differentiate the different spectrum of clinical findings necessary for the case definition of $\mathrm{OM}$ also limits the health workers' ability to make better diagnosis and classification of OM [6]. Ear infection can be classified in different ways depending on the duration of illness, and the type of clinical manifestation the patient is having or otoscopic findings [6]. In Ethiopia and other developing countries, one of the commonly used classification of ear infection is the one depending on the duration of illness, which classifies ear infection into acute ear infection (symptoms lasting for less than 14 days) and chronic ear infection (symptoms lasting for $\geq 14$ days) $[7,8]$. Empiric treatment of ear infection is not always appropriate since drug susceptibility patterns change overtime and empiric antibiotic therapy may not be effective at times and could contribute to development of antimicrobial resistance in the long run $[9,10]$. Early, prompt and effective treatment of ear infection will significantly reduce both short and long term complications associated with ear infection and can also improve the quality of life of patients with ear infection. Thus, having up-to-date information on the etiologies responsible for ear infection and their antimicrobial susceptibility pattern is crucial. This study was done with an objective of determining the bacterial profile, antimicrobial susceptibility pattern and associated factors of ear infections among patients of all age groups visiting health institutions found in Jimma Town, Ethiopia during the study period with a complaint of ear discharge.

\section{Methods}

\section{Study design, period and area}

A prospective cross-sectional study was conducted at Jimma Town from February to September 2017 in five public health institutions: two hospitals (Jimma University Medical Center and Shanan Gibe Hospital) and three public health centers (Jimma, Higher-2, and Mendera Kochi Health Centers) that provide health services for the residents of Jimma Town and surrounding. All the health facilities give services to both children and adults. Majority of the patients coming to the health centers and Shanan Gibe Hospital are residents of Jimma Town whereas those coming to the Jimma University Medical Center (JUMC) could come from the town as well as the surrounding towns or rural areas.

\section{Study participants and data collection}

We used consecutive sampling technique where we approached every patient coming with ear discharge during the study period. We used the presence of an ear discharge as an entry point since routine otoscopic examination might not be carried out in many of the health facilities even if this approach undermines the magnitude of ear discharge as we might have missed some patients who didn't have an obvious ear discharge. Thus, the study participants were patients of all age category with a presumptive/clinical diagnosis of draining $\mathrm{OM}$ who were willing to give consent to participate in the study (parents'/care takers' consent was taken in case of children). The relevant patient information was collected by trained nurses, while the swabs were collected by nurses at the health centers and by ENT doctor and GPs at the two hospitals. Otoscope and headlight were used during specimen collection at one of the health facilities (JUMC) whereas naked eyes were used at the other health facilities since these equipment were not available at these health facilities. We classified ear infection as acute if the duration of discharge was $<14$ days and chronic if the duration of discharge was $\geq 14$ days based on the classifications we use locally $[7,8]$. All the relevant history and physical examinations were done by the treating health workers and the investigators just collected the necessary information for the study.

\section{Isolation and identification of bacteria}

Ear discharge was collected under strict aseptic technique using single use commercially available sterile cotton swabs with utmost care to avoid surface contamination 
(i.e. first cleanse the external ear canal with antiseptic solution and then the pinna was pulled outward and backward to make it more straight forward for taking the ear swab, then sterile cotton swabs were gently rotated and taken out) and then immediately immersed into Amies transport media with charcoal (Oxoid, England).Within 2 $\mathrm{h}$ of collection, swabs were transported to the microbiology laboratory of JUMC, inoculated on blood agar, chocolate agar, and MacConkey agar. The MacConkey and blood agar plates were incubated in aerobic condition, whereas chocolate agar plate was kept in a candle jar, which was able to generate about $5-10 \% \mathrm{CO}_{2}$. All of the inoculated media were incubated at $37^{\circ} \mathrm{C}$ for $18-24 \mathrm{~h}$. All organisms grown were identified according to the standard microbiological methods by using Gram staining reaction, culture characters, colony morphology, pigment production, and type of hemolysis on blood agar. Moreover, conventional biochemical tests like Catalase, Coagulase, Optochin and bacitracin test for gram-positive bacteria and Oxidase test, Triple Sugar Iron Agar (TSI) (OXOID, UK), Citrate utilization test (OXOID, UK), Urease test (OXOID, UK) and Motility Indole Lysine (MIL) [OXOID, UK]) for gram-negative bacteria were used for identification [11].

\section{Antimicrobial susceptibility testing}

Antibiotic susceptibility testing was carried out using Kirby Bauer disc diffusion technique on Muller Hinton agar (Oxoid, England) [12]. Antibiotic discs were selected based on prescription pattern in the study area and recommendations from Clinical Laboratory Standards Institute (CLSI) and European Committee on Antimicrobial Susceptibility Testing (EUCAST) [13]. Accordingly, Penicillin G (P-10 U), Cefoxitin (FOX-30 $\mu \mathrm{g})$, Ampicillin $(\mathrm{AM}-10 \mu \mathrm{g})$, Amoxicillin(AMX-10 $\mu \mathrm{g})$, Erythromycin $(\mathrm{E}-15 \mu \mathrm{g})$, Clindamycin $(\mathrm{CC}-2 \mu \mathrm{g})$, Trimethoprim sulphamethoxazole (SXT-25 $\mu \mathrm{g})$, Oxacillin (OX-1 $\mu \mathrm{g})$, Amoxicillin plus clavulinic acid (Augmentin) (AmC-20/10 $\mu \mathrm{g}$ ), Cefuroxime (CXM-30 $\mu \mathrm{g})$, Ceftriaxone (CRO-30 $\mu \mathrm{g})$, Ceftazidime (CAZ-30 $\mu \mathrm{g})$, Gentamicin (GM-10 $\mu \mathrm{g})$, Tobramycin (TOB-10 $\mu \mathrm{g}$ ), Ciprofloxacin (CIP-5 $\mu \mathrm{g})$, Vancomycin(V-30 $\mu \mathrm{g})$, Amikacin (AK-30 $\mu \mathrm{g})$, Cefepime (CFP-30 $\mu \mathrm{g})$, and Chloramphenicol $(\mathrm{C}-30 \mu \mathrm{g})$ were used. All the antimicrobials used for the study were obtained from Oxoid Ltd., Basingstoke, Hampshire, UK. Reference strains of E. coli ATCC 25922 and S. aureus ATCC 25923 were used for quality control for antimicrobial susceptibility tests. The microbiologic results of each patient were returned back to the health workers treating the patients so that they can modify the treatment of the patients accordingly.

\section{Statistical analysis}

The data was checked for completeness, coded, cleaned and entered into Epi-Data version 3.1 and then exported to and analyzed using SPSS version 22.0. Descriptive statistics such as frequency, percentage and cross tabulation were used to present the findings. Chi-square test was performed to evaluate the presence of statistically significant association and $P$-value less than 0.05 was considered as statistically significant.

\section{Results}

A total of 173 patients with ear discharge participated in this study, out of which 109 (63\%) were children < 14 years. Participants' age ranged from 2 months to 70 years with a mean age of 12.8 years and median of 7 years. Most study subjects were in the age group of $<4$ years (41.61\%). Majority had unilateral 134 (77.46\%), chronic $100(57.8 \%)$ and purulent 113 (65.3\%) ear discharge. Acute ear infection was more common in those $<4$ years (53.8\%) whereas chronic ear infection was more commonly seen in the age group of $15-44$ years (34.6\%). History of previous visit to health care facilities related to ear infection within 2 month period was noted among $102(58.96 \%)$ patients and these patients had reportedly been treated with one or more antimicrobial agents, the most commonly prescribed antibiotics being amoxicillin, followed by amoxicillin-clavulanic acid (Table 1).

The chi-square test indicated that adult age $(p=$ $0.031)$, rural residence $(p=0.005)$, previous history of health care visit and treatment $(p=0.000)$, upper respiratory tract infection $(p=0.018)$ and presence of cigarette smoker in the house $(p=0.022)$ had statistically significant association with chronic ear infection rather than acute ear infection (Table 2).

Among 173 of the study participants, 179 bacterial agents were isolated from 160 (92.5\%) patients. Citrobacter spp. and Coagulase negative Staphylococcus were the predominant organisms isolated from patients with acute ear infection whereas $P$. vulgaris, $P$. mirabilis and $P$. aeruginosa were the predominant organisms isolated from patients with chronic ear infection. Among the culture positive swabs, $89.02 \%$ demonstrated single organisms, while the remaining 10.98\% were positive for two organisms The rates of poly-microbial infection among acute and chronic ear infection cases were 12 (7.5\%) and 7 (4.4\%), respectively. Out of the 179 bacterial isolates, 12 different pathogenic bacterial species were identified. Among the isolated pathogens, Gram-negative bacteria 101 (56.4\%) were predominant isolates than Gram-positives 78 (43.6\%), with the ratio of $\sim 1.3: 1$. The predominant bacterial isolate was $S$. aureus (30.72\%) followed by Proteus spp. (17.89\%), and P. aeruginosa (10.61\%) (Table 3).

Antimicrobial susceptibility test was done for 19 different types of antibiotics. From all the antimicrobials tested, ampicillin/amoxicillin showed the highest resistance rate $(88.1 \%)$ followed by penicillin $\mathrm{G}(79.5 \%)$ and cotrimoxazole (75.8\%). Conversely, the majority of bacterial isolates 
Table 1 Socio-demographic characteristics and clinical manifestations of patients with ear discharge at Jimma Town health facilities, Jimma, Southwest, Ethiopia $(N=173)$

\begin{tabular}{|c|c|}
\hline VARIABLES & FREQUENCY (\%) \\
\hline \multicolumn{2}{|l|}{ Sex } \\
\hline Male & 89 (51.44\%) \\
\hline Female & $84(48.56 \%)$ \\
\hline \multicolumn{2}{|l|}{ Age in years } \\
\hline $0-4$ & $72(41.61 \%)$ \\
\hline $5-9$ & $20(11.56 \%)$ \\
\hline $10-14$ & $17(9.82 \%)$ \\
\hline $15-44$ & $56(32.36 \%)$ \\
\hline$>45$ & $8(4.63 \%)$ \\
\hline \multicolumn{2}{|l|}{ Residence } \\
\hline Urban & $125(72.25 \%)$ \\
\hline Rural & $48(27.75 \%)$ \\
\hline \multicolumn{2}{|c|}{ Previous health care visit and treatment history } \\
\hline Yes & $102(58.96 \%)$ \\
\hline No & $71(41.04 \%)$ \\
\hline \multicolumn{2}{|l|}{ Ear involvement } \\
\hline Right & $76(43.93 \%)$ \\
\hline Left & $58(33.53 \%)$ \\
\hline Both & 39 (22.54\%) \\
\hline \multicolumn{2}{|c|}{ Duration of ear discharge } \\
\hline$<14$ days & $73(42.2 \%)$ \\
\hline$\geq 14$ days & $100(57.8 \%)$ \\
\hline \multicolumn{2}{|l|}{ Discharge type } \\
\hline Purulent & $113(65.32 \%)$ \\
\hline Watery & $25(14.45 \%)$ \\
\hline Mucoid & $25(14.45 \%)$ \\
\hline Blood stained & $10(5.78 \%)$ \\
\hline \multicolumn{2}{|l|}{ Odor of discharge } \\
\hline Non-foul smelling & 69 (39.88\%) \\
\hline Foul smelling & 104 (60.12\%) \\
\hline
\end{tabular}

were susceptible to ciprofloxacin (72.9\%), gentamicin (70.4\%), and amikacin (69.3\%).

Overall, gram-positive isolates revealed variable degree of resistance to the antimicrobials tested ranging from as low as $11.1 \%$ (for S. pyrogens' resistance to ampicillin, ceftriaxone, gentamicin and penicillin G) and as high as 92.7\% (S. aureus' resistance to ampicillin, and penicillin G). Among gram-positive bacteria, increased level of resistance was found to Trimethoprim-sulphamethoxazole (78.2\%), amoxicillin/ampicillin (76.9\%) and penicillin G (79.5\%) whereas relatively high sensitivity was seen to ceftazidime (66.7\%), ciprofloxacin (70\%), and gentamicin (79.5\%). Out of $55 \mathrm{~S}$. aureus isolated, 36 (65.5\%) were Methicillin Sensitive $S$. aureus (MSSA) whereas the
Table 2 Variables identified as having statistically significant relationship to the type of ear infection cases at Jimma Town health facilities, Jimma, Southwest, Ethiopia, $(N=173)$

\begin{tabular}{cccc}
\hline Variable & \multicolumn{2}{l}{ Type of ear infection } & $\begin{array}{c}p \text { - } \\
\text { value }\end{array}$ \\
\cline { 2 - 3 } Acute ear infection & Chronic ear infection & \\
\hline $0-4$ & 39 & 35 & 0.031 \\
$5-9$ & 6 & 14 & \\
$10-14$ & 6 & 10 & \\
$15-44$ & 22 & 33 & \\
$>45$ & 0 & 8 & 0.005 \\
Residence & & & \\
Urban & 61 & 64 & 0.000 \\
Rural & 12 & 36 & \\
Previous health care visit and treatment history & \\
Yes & 27 & 76 & 0.018 \\
No & 46 & 24 & \\
Upper respiratory tract infection & & \\
Yes & 22 & 48 & \\
No & 51 & 52 & \\
Smoker in the house & 5 & 19 & \\
Yes & 68 & 81 & \\
No & & & \\
\hline
\end{tabular}

remaining 19 (34.5\%) were Methicillin-Resistant S. aureus (MRSA). The majority (88.9\%) of S. pyogenes isolates were sensitivity to penicillin $G$ (Table 4 ).

Among gram-negative isolates, maximum level of resistance was seen towards ampicillin (by $P$. vulgaris, $P$. mirabilis, Klebsiella spp., Providencia spp., Citrobacter spp., Enterobacter spp., and M. morganii) and ceftriaxone (by $P$. aeruginosa), whereas better susceptibility was seen to ciprofloxacin (93.1\%), amikacin $(80.2 \%)$, gentamicin (80.2\%) and cefepime (64.4\%). Proteus spp., the second most frequently isolated bacterium, showed increasing resistance rate to each of the following antibiotics: amoxicillin/ampicillin (100\%), trimethoprimsulphamethoxazole (65.6\%) and chloramphenicol (59.4\%); however, it showed high sensitivity to ciprofloxacin, gentamicin, and amikacin. P. aeruginosa, the third most common isolates, showed resistance rates to ceftriaxone and cefotaxime (100\%), ceftazidime (71.4\%) and cefepime (64.3\%), but sensitive for gentamicin (85.7\%), ciprofloxacin and amikacin (each with 78.6\%). E. coli isolates, showed resistance rates of $88.9 \%$ to amoxicillin; however, was seen equally sensitive to chloramphenicol, amikacin, ceftazidime, ciprofloxacin. Providencia spp., Citrobacter spp., Enterobacter spp. and Klebsiella spp. were highly resistant to amoxicillin (100\%) and amoxicillin/clavulanic acid (62.5-87.5\%). On the other hand, Citrobacter spp. and Enterobacter spp. 


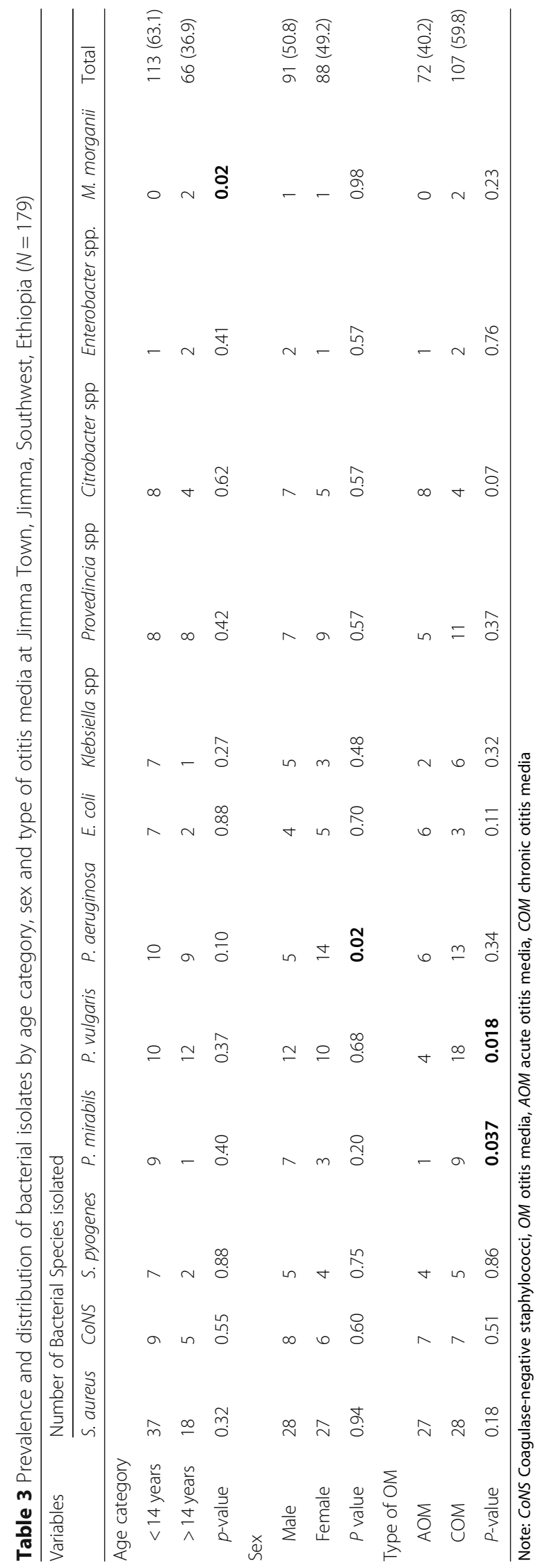


Table 4 Antimicrobial resistance patterns of gram-positive bacterial isolates ( $n=78)$ from suspected otitis media patients with discharge at Jimma Town, Jimma, Southwest, Ethiopia

\begin{tabular}{|c|c|c|c|c|c|c|c|c|c|c|c|c|c|c|c|c|}
\hline \multirow{2}{*}{$\begin{array}{l}\text { Bacterial } \\
\text { isolates }\end{array}$} & \multirow{2}{*}{$\begin{array}{l}\text { Total No. } \\
\text { isolates }\end{array}$} & \multicolumn{15}{|c|}{ Resistance pattern of antimicrobial agents (\%) } \\
\hline & & AMP & AMC & CRO & CIP & FOX & $\mathrm{E}$ & $\mathrm{CN}$ & PG & SXT & DA & OX & TOB & $\mathrm{CTZ}$ & CXM & CFT \\
\hline S. aureus & 55 & 92.7 & 34.5 & 34.5 & 27.3 & 34.5 & 58.2 & 23.6 & 92.7 & 80 & 43.6 & 34.5 & 40 & 34.5 & 34.5 & 34.5 \\
\hline CONS & 14 & 57.1 & 35.7 & 28.6 & 35.7 & 28.6 & 57.1 & 14.3 & 71.4 & 78.6 & 50 & 28.6 & 21.4 & 28.6 & 28.6 & 28.6 \\
\hline S. pyogenes & 9 & 11.1 & NA & 11.1 & NA & NA & 33.3 & 11.1 & 11.1 & 66.7 & 33.3 & NA & NA & NA & NA & NA \\
\hline Total & 78 & 76.9 & 34.8 & 30.8 & 30 & 33.3 & 55.1 & 20.5 & 79.5 & 78.2 & 43.6 & 33.3 & 36.2 & 33.3 & 33.3 & 33.3 \\
\hline
\end{tabular}

Note: CoNS Coagulase-negative staphylococci, $A M P$ ampicillin/amoxicillin, $A M C$ amoxicillin clavulanic acid, CRO ceftriaxone, CIP ciprofloxacin, FOX cefoxitin, $E$ erythromycin, $C N$ gentamicin, $P G$ penicillin G, SXT sulfamethoxazole-trimethoprim, DA clindamycin, $O X$ oxacillin, TOB tobromycin, $C A Z$ ceftazidime, $C X M$ cefuroxime, CFT cefotaxime, NA not applicable

showed high level of sensitivity to gentamicin, ceftazidime, and amikacin (Table 5).

From the total bacterial isolates, 120 (67\%) had shown MDR features; Proteus spp. and S. aureus being the predominant organisms demonstrating MDR pattern (84.4 and $74.5 \%$, respectively). The overall observed MDR rate among gram-positive and gram-negative bacterial isolates was similar (66.7 and 67.3\%, respectively) (Fig. 1).

\section{Discussion}

In the present study, the highest percentage of ear infection was found among pediatric patients (63\%) and this agrees with reports from other parts of Ethiopia [3, 4, 14-17]. In addition, the majority of bacterial isolates were identified in the age group <4years (41.61\%) which is also in line with other previous studies $[4,15,16,18,19]$, although a study done in Dessie (Ethiopia) reported higher frequency in the age group of $16-35$ years $(42.4 \%)$ [20].

In this study, the majority of the patients $(57.8 \%)$ had ear discharge for $\geq 14$ days, which is in agreement with previously done studies in Ethiopia, in which COM accounted for $60-83 \%$ of the OM cases [3, 4, 21, 22].
In the present study, the bacterial isolation rate was 92.5\% which was higher than previous studies reported from Hawassa, 52.1\% [14], Bahir Dar 80.4\% [23], Nigeria 81.9\% [24], Dessie 82\% [16], Wollo 83.6\% [20], Gondar 89.5\% [15], Dessie 89.4\% [3] and lower than the reports from Mekelle 98.2\% [4], and Jimma 100\% [22].

In the present study, from the total bacterial isolates, gram-negative bacteria $(56.4 \%)$ were slightly higher than gram-positive bacteria, which is in agreement with previous studies done in various parts of Ethiopia: Mekelle (56\%), Gondar (56.4\%), Bahir Dar (58.8\%), Addis Ababa (60.5\%), Dessie (74.2\%) and (78.7\%), Wollo (75.8\%) and Hawassa $(79.5 \%)$ [3, 4, 14-16, 18, 20, 23]. The leading isolated bacteria in this study was S. aureus (30.72\%), followed by Proteus spp. (17.89\%) and P. aeruginosa (10.61\%), similar to reports of other investigators from Mekelle and Addis Ababa $[4,18]$. Unlike our findings, Proteus spp. followed by S. aureus and Pseudomonas spp. were the predominant isolates reported by other researchers from different parts of Ethiopia [3, 15, 16, 20, 22] and relatively different patterns were reported from elsewhere [25-27] with $P$. aeruginosa as the main isolate followed

Table 5 Antimicrobial resistance profiles of gram-negative bacterial isolates $(n=101)$ from suspected otitis media patients with discharge at Jimma Town, Jimma, Southwest, Ethiopia

\begin{tabular}{|c|c|c|c|c|c|c|c|c|c|c|c|c|c|}
\hline \multirow[t]{2}{*}{ Bacterial isolates } & \multirow{2}{*}{$\begin{array}{l}\text { Total No. } \\
\text { isolates }\end{array}$} & \multicolumn{12}{|c|}{ Resistance pattern of antimicrobial agents (\%) } \\
\hline & & AMP & AMC & $\mathrm{CRO}$ & CIP & C & FEP & $\mathrm{CN}$ & $\mathrm{CTZ}$ & SXT & TOB & AK & CXM \\
\hline E. coli & 9 & 88.9 & 33.3 & 33.3 & 11.1 & 11.1 & 22.2 & 33.3 & 11.1 & 77.8 & 66.7 & 11.1 & 44.4 \\
\hline P. vulgaris & 22 & 100 & 59.1 & 36.4 & 0 & 54.5 & 27.3 & 18.2 & 27.3 & 63.6 & 50 & 18.2 & 59 \\
\hline P. aeruginosa & 19 & NA & NA & 100 & 21.4 & NA & 64.3 & 14.3 & 71.4 & NA & 42.9 & 21.4 & NA \\
\hline P. mirabilis & 10 & 100 & 50 & 50 & 10 & 70 & 50 & 30 & 30 & 90 & 40 & 30 & 70 \\
\hline Klebsiella spp. & 8 & 100 & 62.5 & 37.5 & 0 & 37.5 & 25 & 37.5 & 25 & 62.5 & 25 & 12.5 & 62.5 \\
\hline Providencia spp. & 16 & 100 & 87.5 & 62.5 & 12.5 & 56.3 & 56.3 & 25 & 56.3 & 81.3 & 56.3 & 18.8 & 68.8 \\
\hline Citrobacter spp. & 12 & 100 & 58.3 & 33.3 & 0 & 41.7 & 16.7 & 8.3 & 16.7 & 66.7 & 66.7 & 16.7 & 66.7 \\
\hline Enterobacter spp. & 3 & 100 & 66.7 & 33.3 & 0 & 66.7 & 33.3 & 0 & 0 & 0 & 66.7 & 0 & 66.7 \\
\hline M. morganii & 2 & 100 & 50 & 50 & 0 & 0 & 0 & 0 & 0 & 50 & 0 & 0 & 0 \\
\hline Total & 101 & 98.8 & 61 & 48.5 & 6.9 & 47.6 & 35.6 & 19.8 & 41.6 & 69.5 & 47.5 & 19.8 & 80.6 \\
\hline
\end{tabular}

Note: $A M P$ ampicillin/amoxicillin, $A M C$ amoxicillin clavulanic acid, $C R O$ ceftriaxone, CIP ciprofloxacin, $C$ chloramphenicol, $F E P$ cefepime, $C N$ gentamicin, $C A Z$ ceftazidime, SXT sulfamethoxazole-trimethoprim, TOB tobromycin, $A K$ amikacin, CXM cefuroxime, NA not applicable 


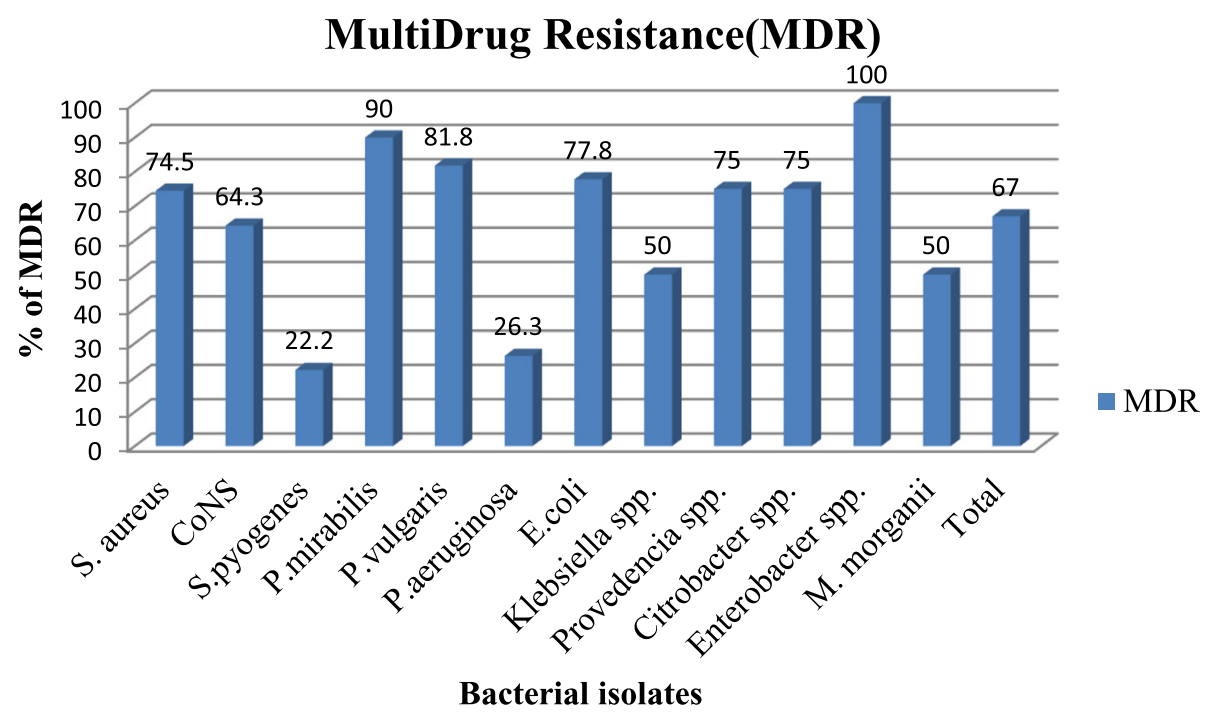

Fig. 1 Multidrug resistance pattern of bacterial pathogens isolated from otitis media at Jimma Town, Jimma, Southwest, Ethiopia ( $N=179)$

by $S$. aureus and Proteus spp. The possible reasons for such variation in the bacterial profile might be attributed to the difference in climatic and geographic variation of the study sites.

In our study, the most prevalent organism responsible for acute ear infection was S. aureus (37.5\%). Even though, the global reports show that $H$. influenzae, $S$. pneumoniae, and M. catarrhalis to be the most prevalent organisms responsible for AOM [3], our findings is in agreement with reports from other African countries that indicate $S$. aureus and $S$. pyogenes were the predominant isolates [28]. The reason for this might be the differences in geographic location, prevalence of respiratory infection, coverage of pneumococcal conjugate vaccine (PCV), and possible overuse of antimicrobials that might have killed the sensitive organism and favored the drug resistant ones to be predominant, biofilm phenotypes property of the $S$. aureus and potentially other local and regional factors.

In the present study, both Proteus spp. (P. vulgaris $(p=0.018)$ and P. mirabilis $(p=0.037))(84.4 \%)$ were more common among the chronic than the acute ear infections. This finding is comparable to Seid et al. from Dessie [3] and Muleta et al. from Jimma [22] who reported rates of 85.4 and $74.5 \%$, respectively and contradicts with Wasihun and Zemene's from Mekele [4] who reported that $P$. mirabilis was seen in $63 \%$ of COM and P. vulgaris in 57\% of AOM. The possible reasons for this might be Proteus spp. were common isolates in patients presenting lately (2 months after onset of ear discharge), as a result patients with discharging ears may not notice immediately for early diagnosis or the antibiotic treatment was not effective [29].
In this study, those with history of previous health care visit and treatments (58.96\%) showed a significant association with chronic ear infection $(p=0.000)$, which is similar to Wasihun's and Zemene's reports [4]. This could probably be due to failure of empiric treatment of AOM. Thus, it might be wise to take a swab if the patient has ear discharge, then begin treating the patient with topical +/- systemic antibiotics according to empirical guidance available. In the meantime, proper etiology based diagnosis should be in place and once the organism is known, appropriate management of ear infection becomes effective. This in turn facilitates the rational use of antibiotics based on recent and local data in our health facilities in order to reduce sequales associated with ear infection [1]. In this study, the isolated bacteria showed highest rate of resistance to the different antibiotics commonly used for OM treatment which is in line with earlier reports from different parts of Ethiopia $[3,4,16,20]$ and a good overall antimicrobial susceptibility pattern $(>70 \%)$ was seen to gentamicin and ciprofloxacin which is also in line with other studies conducted in Ethiopia [3, 4, 16, 20, 23] and in other countries asuch as Ardebil [30], Iraq [31], Nepal [32], India [33], and Jordan [34]). In contrast to these reports, gentamicin and ciprofloxacin were reported as ineffective from a study conducted in Nigeria [24].

In the present study, $34.5 \%$ of $S$. aureus were MRSA, similar to a report by Hailu et al. (34.6\%) from Bahir Dar [23]. On the other hand, S. aureus exhibited high levels of resistance to ciprofloxacin (27.3\%) which is significantly higher compared with other reports which showed resistance rates as high as $21 \%[3,4,15,16,23]$. Many of the isolates showed high levels of sensitivity to gentamicin, which is consistent with other reports 
[14-16]. Moreover, the observed high level of resistance for clindamycin (43.6\%), erythromycin (58.2\%) and trimethoprim-sulphamethoxazole $(80 \%)$ is also higher than other studies $[3,4,15,16,22]$.

Overall, $67 \%$ of the bacterial isolates from this study were characterized as MDR pathogenic bacteria. The reason for this might be linked to a prescription of antibiotics without laboratory guidance, purchasing of drugs without proper prescription (self-medication) in the local pharmacies and drug stores, misuse of antibiotics, indiscriminate use of antibiotics including animal husbandry, inappropriate prescribing habits and an over-zealous desire to treat every infection using antibacterial agents. Moreover, biofilm bacterial properties of common isolates, unavailability of bacterial culture facilities and poor infection prevention and control practices may be some of the different factors that can contribute to the development of MDR among these isolates.

The limitations of this study include the fact that we did not include the OME and OM without discharge as well as the fact that we did not try to isolate strict anaerobic bacteria and fungi which might also be the possible causative agents for OM. Additionally, we didn't intend to differentiate $\mathrm{OM}$ from otitis externa.

\section{Conclusion and recommendation}

S. aureus, Proteus spp. and P. aeruginosa were the three predominant bacterial isolates from patients with ear discharge. The profile and predominant bacteria isolated highlights the need for continuous surveillance and reporting of the microbiology of ear infection in our local community in order to guide clinicians use the appropriate antimicrobials towards the incriminated etiologies. The pathogens which have been isolated from ear discharge have shown a high level of antibiotics resistance and MDR features in the study area. Almost all the isolated bacteria showed a considerable level of resistance particularly to the commonly used antibiotics like ampicillin, amoxicillin, amoxicillin/clavulanic acid, and trimethoprim-sulfamethoxazole. Ciprofloxacin, amikacin and gentamicin are effective against all the bacterial isolates. In general, the result of this study revealed that antibiotic-resistant bacteria recovered from patients with ear infection are alarmingly increasing in Jimma area and becoming a major public health problem in the management of patients with a middle ear infection. Due to the increase in resistance to antibiotics one can advocate to swab the ear first and wait for the result especially if the patient has already had treatment as shown by our data which is often the case. We strongly recommend nationwide antimicrobial surveillance to make the right recommendation of antibiotics along with strict adherence to antibiotic use policy to reduce the spread of drug-resistant microbes and associated complications in the country. Hence, parallel to empiric treatment of ear infection, execution of culture and antimicrobial susceptibility test shall be taken as routine and mandatory practice in order to appropriately manage ear infection, reduce associated complications (individual, household, and health system) and reduce emergence of drug resistance in the community. Moreover, in the new cases we recommend taking swab before starting a regime based treatment in case there is already resistance. Further researches are needed to identify high resistance strains and characterization of resistance strains using molecular techniques.

\section{Abbreviations \\ AOM: Acute otitis media; ATCC: American Type Culture Collection; CLSI: Clinical Laboratory Standards Institute; COM: Chronic otitis media; EUCAST: European Committee on Antimicrobial Susceptibility Testing; MDR: Multidrug resistance; MRSA: Methicillin-Resistant S. aureus; MSSA: Methicillin Sensitive S. aureus; OM: Otitis media; OME: Otitis media with effusion; RAOM: Recurrent acute otitis media}

\section{Acknowledgements}

The authors are grateful to all study participants for their willingness to participate in this study. Additionally, we would like to thank the staff of Jimma University Medical Center (ENT staff and Bacteriology unit). We are also grateful to Dr. Tesfaye kassa and Dr. Solomon Ali for their constructive comments and suggestions during laboratory examination and result analysis.

\section{Funding}

The research was funded by Institute of Health, Jimma University.

\section{Availability of data and materials}

All data generated or analyzed during this study are included in this manuscript, except few sensitive information like name (s) of the study participants linked to their ear discharge results.

\section{Authors' contributions}

KG generated the research idea, wrote the proposal, participated in data collection, analysis, interpretation, and drafting of the manuscript. All other authors participated in data collection and analysis, and interpretation and critical review of the manuscript. In addition ZM and GB were part of the initiation of the research idea. Finally all the authors have critically reviewed the manuscript and overall write-up. All of them read and approved the final manuscript.

\section{Ethics approval and consent to participate}

Ethical clearance was obtained from the institutional review board (IRB) of Institute of Health, Jimma University (Ref no: IHRPGC/280/071) and permission was obtained from the health facilities where the study was conducted.

Informed voluntary assent was obtained from children and written consent was obtained from all adult patients and parents/guardians of the children involved before commencing the study. Patients with a positive result were communicated about their result to their respective health professional/ physician for proper management.

\section{Consent for publication}

Not applicable.

\section{Competing interests}

The authors declare that they have no competing interests.

\section{Publisher's Note}

Springer Nature remains neutral with regard to jurisdictional claims in published maps and institutional affiliations. 


\section{Author details}

${ }^{1}$ School of Medical Laboratory Sciences, Institute of Health, Jimma University, P.O. Box 378, Jimma, Ethiopia. 'Department of Pediatrics and Child Health, Institute of Health, Jimma University, Jimma, Ethiopia.

\section{Received: 17 May 2018 Accepted: 13 November 2018}

Published online: 04 December 2018

\section{References}

1. Monasta $L$, et al. Burden of disease caused by otitis media: systematic review and global estimates. PLoS One. 2012;7(4):e36226.

2. Cripps AW, Kyd J. Bacterial otitis media: current vaccine development strategies. Immunol Cell Biol. 2003:81(1):46-51.

3. Seid A, et al. Bacterial otitis media in all age group of patients seen at Dessie referral hospital, north East Ethiopia. Egyptian Journal of Ear, Nose, Throat and Allied Sciences. 2013;14(2):73-8.

4. Wasihun AG, Zemene $Y$. Bacterial profile and antimicrobial susceptibility patterns of otitis media in Ayder teaching and referral hospital, Mekelle University. Northern Ethiopia Springerplus. 2015;4(1):701.

5. Chirwa M, et al. Microbiology of chronic suppurative otitis media at queen Elizabeth central hospital, Blantyre, Malawi: a cross-sectional descriptive study. Malawi Med J. 2015;27(4):120-4.

6. Bervnan, S., Classification and criteria of otitis media. Clinical Microbiology and Infection, 1997. 3: p. 351-3S4

7. Costello A. Integrated management of childhood illness. Lancet. 1997; 350(9087):1266

8. Acuin, J. and W.H. Organization, Chronic suppurative otitis media: burden of illness and management options. 2004.

9. Grevers $\mathrm{G}$. Challenges in reducing the burden of otitis media disease: an ENT perspective on improving management and prospects for prevention. Int J Pediatr Otorhinolaryngol. 2010;74(6):572-7.

10. Agrawal A, et al. Microbiological profile and their antimicrobial sensitivity pattern in patients of otitis media with ear discharge. Indian Journal of Otology. 2013;19(1):5.

11. Cheesbrough M. District laboratory practice in tropical countries: Cambridge university press; 2006.

12. Cockerill FR, Wikler MA, Bush K, Dudley MN, Eliopoulos GM, Hardy DJ, et al. Performance Standards for Antimicrobial Susceptibility Testing Twenty-First Informational Supplement 2011.

13. CLSI. Performance Standards for Antimicrobial Susceptibility Testing. Clinical and Laboratory Standards Institute. 2016;39-43.

14. Worku M, Bekele M. Bacterial isolate and antibacterial resistance pattern of ear infection among patients attending at Hawassa university referral hospital, Hawassa. Ethiopia Indian Journal of Otology. 2014:20(4):155.

15. Muluye $D$, et al. Bacterial isolates and drug susceptibility patterns of ear discharge from patients with ear infection at Gondar University Hospital, Northwest Ethiopia. BMC Ear, Nose and Throat Disorders. 2013;13(1):10.

16. Abera B, Kibret M. Bacteriology and antimicrobial susceptibility of otitis media at Dessie regional health research laboratory. Ethiopia Ethiopian Journal of Health Development. 2011:25(2):161-7.

17. Pedersen TM, et al. Antibiotics in Pregnancy Increase Children's Risk of Otitis Media and Ventilation Tubes. The Journal of pediatrics. 2017:183:153-8 e1.

18. Ferede $D$, et al. Drug susceptibility pattern of bacterial isolates from children with chronic suppurative otitis media. Ethiop J Health Dev. 2001;15(2):89-96.

19. Tesfaye G, et al. Microbiology of discharging ears in Ethiopia. Asian Pac J Trop Med. 2009;2(1):60-7.

20. Argaw-Denboba A, Abejew AA, Mekonnen AG. Antibiotic-resistant bacteria are major threats of otitis media in Wollo area, northeastern Ethiopia: a tenyear retrospective analysis. Int J Microbiol. 2016;2016:8724671.

21. Tessema G. Otitis media seen in Yekatit 12 hospital. Ethiop Med J. 2001; 39(2):113-21.

22. Muleta D, Gebre-Selassie S. Isolation and antimicrobial susceptibility patterns of bacterial pathogens causing otitis media in children in Jimma Hospital, Southwestern Ethiopia. Ethiop J Health Sci. 2004;14(2):89-99.

23. Hailu D, et al. Pathogenic bacteria profile and antimicrobial susceptibility patterns of ear infection at Bahir Dar regional Health Research Laboratory center. Ethiopia Springerplus. 2016;5(1):466.

24. Osazuwa $F$, et al. Etiologic agents of otitis media in Benin city, Nigeria. N Am J Med Sci. 2011;3(2):95

25. Aslam MA, Ahmed Z, Azim R. Microbiology and drug sensitivity patterns of chronic suppurative otitis media. J Coll Physicians Surg Pak. 2004;14(8):459-61.
26. Fatima $\mathrm{G}$, et al. Antimicrobial susceptibility pattern of bacterial and fungal isolates from patients with chronic suppurative otitis media in perspective of emerging resistance. Pak J Otolaryngo. 2013;29:49-53.

27. Weckwerth $\mathrm{PH}$, et al. Chronic suppurative otitis media in cleft palate: microorganism etiology and susceptibilities. The Cleft Palate-Craniofacial Journal. 2009;46(5):461-7.

28. Ibekwe T, Nwaorgu O. Classification and management challenges of otitis media in a resource-poor country. Niger J Clin Pract. 2011;14(3):262-9.

29. Mahoney JL. Mass management of otitis media in Zaire. Laryngoscope. 1980;90(7):1200-8.

30. Ettehad G, et al. Microbial and antimicrobial susceptibility patterns from patients with chronic otitis media in Ardebil. Int J Trop Med. 2006;1(2):62-5.

31. Alsaimary IE, Alabbasi AM, Najim JM. Antibiotics susceptibility of bacterial pathogens associated with otitis media. African Journal of Bacteriology Research. 2010;2(4):41-50.

32. Arjyal C, Adhikari S, Shrestha J. Bacteriological study of ear discharge in BIR hospital. Journal of Nepal medical association. 2002;41:318-22.

33. Poorey $V$. Study of bacterial flora in CSOM and its clinical significance. Indian J Otolaryngol Head Neck Surg. 2002;54(2):91-5.

34. Mohammad A. Etiology and antimicrobial susceptibility pattern of otitis media in children at princess Rhamah hospital in Jordan. New Iraqi Journal of Medicine. 2010:6:1.
Ready to submit your research? Choose BMC and benefit from:

- fast, convenient online submission

- thorough peer review by experienced researchers in your field

- rapid publication on acceptance

- support for research data, including large and complex data types

- gold Open Access which fosters wider collaboration and increased citations

- maximum visibility for your research: over $100 \mathrm{M}$ website views per year

At $\mathrm{BMC}$, research is always in progress.

Learn more biomedcentral.com/submissions 